\title{
Lumbar Disc Prolapse in Adolescent Patients
}

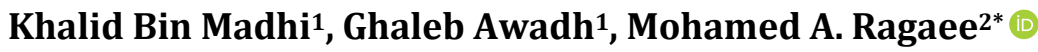 \\ ${ }^{1}$ Neurosurgery Department, Hadhramout University, Hadhramout, Yemen \\ ${ }^{2}$ Neurosurgery Department, Assiut University, Assiut, Egypt \\ Email: *mohamedragaee1980@hotmail.com
}

How to cite this paper: Madhi, K.B., Awadh, G. and Ragaee, M.A. (2019) Lumbar Disc Prolapse in Adolescent Patients. Open Journal of Modern Neurosurgery, 9 , 472-479.

https://doi.org/10.4236/ojmn.2019.94046

Received: September 14, 2019

Accepted: October 28, 2019

Published: October 31, 2019

Copyright $\odot 2019$ by author(s) and Scientific Research Publishing Inc. This work is licensed under the Creative Commons Attribution International License (CC BY 4.0).

http://creativecommons.org/licenses/by/4.0/

\begin{abstract}
Objective: To discusses the surgical treatment of prolapsed lumber intervertebral disc in adolescents and its long-term results (PLID). Background: PLID is very rare in adolescence. Heavy lifting and trauma are the main causes; back pain and radicular pain are the most common clinical presentations, and surgical treatment gives satisfactory outcome after failure of conservative treatment. Methods: During period from January 2014-January 2019 twenty patients between 14 - 20 years old underwent for lumbar disc surgery in Neurosurgery department, Hadramawt University, Yemen, 18 patients were males while 2 were females. Results: Twenty patients 18 males (80\%) while 2 females (20\%) all patients have low back pain (100\%), unilateral sciatica in (90\%), bilateral sciatica in (10\%) and sphincter disturbance in (10\%). The most common affected level is L4/5 represent (80\%) while L5/S1 (20\%), partial lumbar laminectomy in (40\%) and microdiscectomy and fenestration in (60\%). Complication rate was (15\%) and recurrence only (5\%). Conclusion: PLID in adolescence is very rare; back pain and sciatica were the main clinical presentation. Meticulous surgical procedures give satisfactory outcome and excellent result.
\end{abstract}

\section{Keywords}

Lumber Disc, Adolescents, Sciatica, Microdiscectomy

\section{Introduction}

Lumbar disc herniation is one of the most common disease in elderly people, but very rare in adolescent and children [1].

Adolescent patients represent $0.5 \%-6.8 \%$ of all PLID patients [2] [3].

Numerous studies reported early diagnosis and surgical treatment contribute excellent results. 
The commonest etiology of PLID in adolescent was heavy lifting and trauma. Clinical presentation was law back pain and radicular pain [4].

Conservative treatment is the recommended first choice treatment for six to twelve weeks [3].

Surgery is recommended in case of failure conservative treatment and occurrence of any neurological deterioration. The goal of surgical treatment for adolescent lumbar disc herniation is to make immediate relieve of symptoms and allow early return to school [3]. Due to rarity of this condition worldwide, a few reports discuss this adolescent's health problem and there is still controversy regarding the ideal treatment plane. Dang L. et al. mentioned that conservative treatment usually takes long time and results may not be satisfactory to some patients at the end of treatment. Also there is some controversy about the long term results of surgical treatment and the recurrence of the disc prolapse with the problem of decreasing the disc height and adjacent level disease [3] [4]. The aim of this study is to review our short and long term results in surgical treatment of PLID in adolescent patients and review the efficacy and safety of surgical treatment.

\section{Patients and Method}

In this retrospective descriptive study, we reviewed all patents presented with PLID and treated in department of Neurosurgery in Hadramawt University, Yemen in a period of 5 years (January 2014 to January 2019), we found that only 20 adolescents (18 males, 2 females) presented with PLID and treated surgically after failed conservative treatment, with Age range between 14 - 20 years old diagnosed with prolapsed lumber intervertebral disc (PLID).

All patients treated by conservative treatment for at least 6 weeks.

Intractable back pain, sciatica, failure to respond to conservative treatment after 6 weeks and presence of any sphincter disturbance and/or weakness were indication for surgery.

Detailed history, Clinical examination and Imaging of lumbosacral spine were done for all patients. Magnetic resonance imaging (MRI) of lumbosacral spine was the imaging technique of choice for all patients (Figures 1-3). All patients did a dynamic $x$-ray of the lumbosacral spine.

All patients prepared for surgery by doing complete routine blood investigations and preoperative physical fitness. All patients and their first-degree relatives informed about their condition, the disease, about the risks of surgery and anesthesia and also informed about the other treatment options. All patients signed an informed consent.

The main surgical approach was interlaminar approach and fenestration for most of patients. We used it as a minimal invasive approach for microdiscectomy. Some patients had a stenosis of the spinal canal in association with the PLID and in those cases we had to do partial laminectomy with the discectomy. 


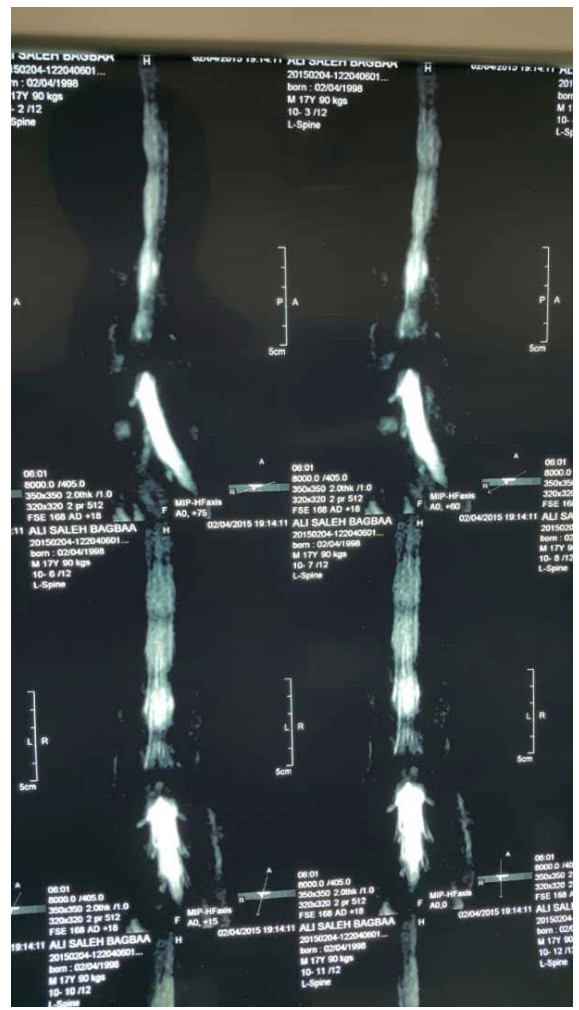

Figure 1. MRI lumbosacral spine myelogram of male patient 18 years old with $\mathrm{L} 4 / 5$ disc herniation.

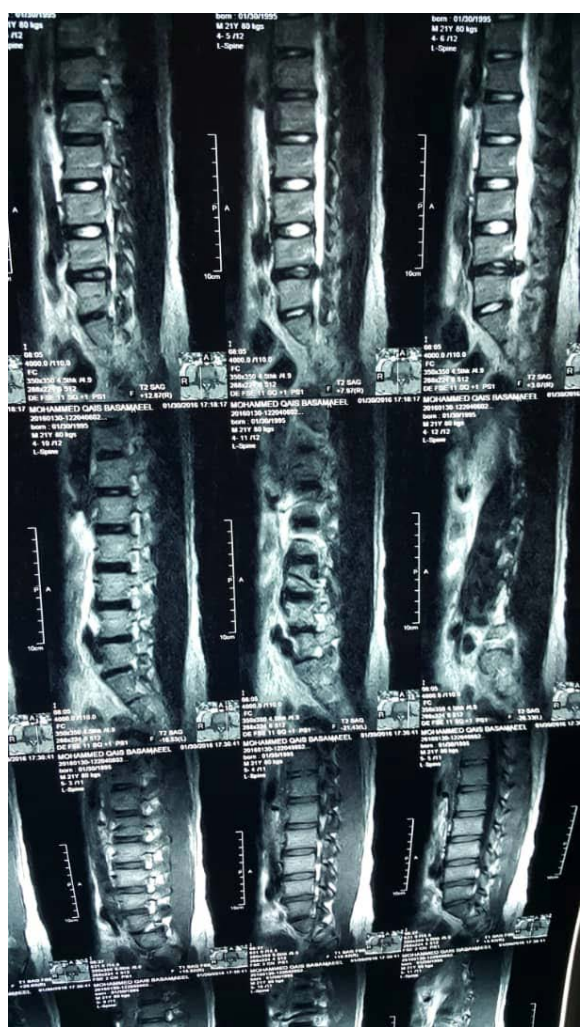

Figure 2. MRI lumbosacral spine, sagittal view of male patient 15 years old with $\mathrm{L} 4 / 5$ disc herniation. 


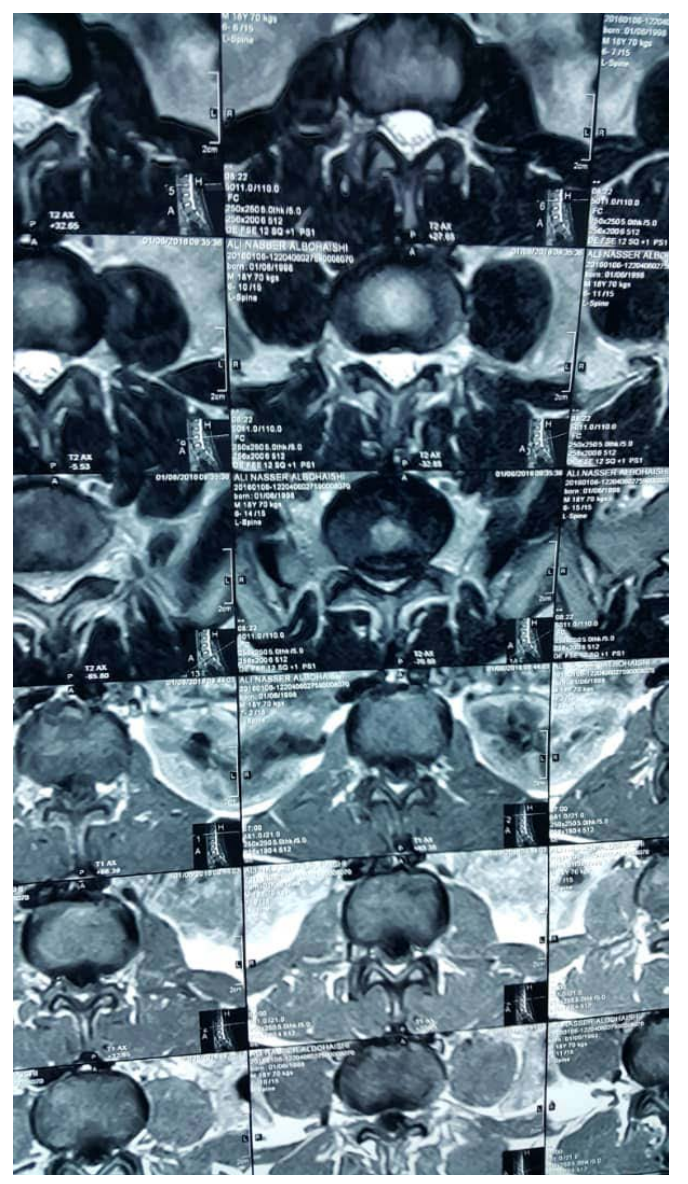

Figure 3. MRI lumbosacral spine, axial view of male patient 16 years old with L5/S1 disc herniation.

\section{Result}

In this study, patients were 18 males (90\%) and 2 females (10\%). Regarding to age distribution the most common affected age group was between 18 - 20 years 10 patients (50\%), between $16-18$ years old 6 patients $(30 \%)$ and $14-16$ years old only 4 patients (20\%) (Table 1 ).

L4/5 level is the most commonly affected level (80\%), then L5/S1 level (20\%). 14 patients $(70 \%)$ had protruded or extruded lateral disc prolapse, while 6 patients (30\%) had central disc prolapsed (Table 2).

According to clinical presentation in our study the back pain was the most common complaint represent $(100 \%)$ of patients, followed by unilateral sciatica represent $(90 \%)$ of patients, then bilateral sciatica represents (10\%) of patients.

Two patients presented with sphincter disturbance (10\%), one presented with urine retention and the other patient presented with urgency of urine and both of them presented to us within the first 48 hours after start of the urinary symptoms. Both of them improved after surgery (Table 3 ).

Regarding the operative approach, we did microdiscectomy to 12 patients $(60 \%)$ and we had to do partial laminectomy and discectomy for 8 patients (40\%) (Table 4). 
Table 1. Age and sex distribution.

\begin{tabular}{ccccc}
\hline & \multicolumn{4}{c}{ Sex distribution } \\
\cline { 2 - 5 } Age group & \multicolumn{3}{c}{ Male } & Female \\
\cline { 2 - 5 } & No. & $\%$ & No. & $\%$ \\
\hline $14-16$ & 4 & 20 & - & - \\
$16-18$ & 6 & 30 & 2 & - \\
$18-20$ & 8 & 40 & 2 & 10 \\
Total & 18 & 90 & & 10 \\
\hline
\end{tabular}

Table 2. Levels of lumber disc.

\begin{tabular}{ccc}
\hline Disc level & No. & $\%$ \\
\hline L4-5 & 16 & 80 \\
L5-S1 & 4 & 20 \\
Total & 20 & 100 \\
\hline
\end{tabular}

Table 3. Clinical presentation.

\begin{tabular}{cccccc}
\hline Clinical presentation & & No. & $\%$ & Rt. & Lt. \\
\hline Back pain & +ve & 20 & 100 & - & - \\
Unilateral sciatica & +ve & 18 & 90 & 14 & 4 \\
Bilateral sciatica & +ve & 2 & 10 & - & - \\
Sphincter dist & +ve & 2 & 10 & - & - \\
\hline
\end{tabular}

Table 4. Type of surgery.

\begin{tabular}{ccc}
\hline Type of surgery & No. & $\%$ \\
\hline Partial lumbar laminectomy & 8 & 40 \\
Fenestration and microdiscectomy & 12 & 60 \\
\hline
\end{tabular}

\section{Outcome and Follow $U p$}

The mean follow up period was 1 year \pm 6 months. All patients did an MRI follow up after 6 months of surgery. All patients were asked about their pain immediately after surgery (after 2 days and during the follow up period), back pain and sciatica improved in all patients immediately after surgery except 3 patients (15\%) with minimal post-operative back pain and improved sciatica. The 3 patients with back pain improved gradually within the follow up period by using medical treatment and physiotherapy. 2 patients (10\%) with sphincter disturbance improved after surgery.

\section{Recurrence}

We had recurrence only in one patient (5\%), male patient had L4/5 disc and complaint of left sciatica, post-operative he was improved, after 2 years he presented with back pain and right sciatica. 


\section{Discussion}

Lumbar intervertebral disc herniation is the most common disorder in adult with life time occurrence about $40 \%$, but rare in adolescent and young population $(0.5 \%-6.8 \%)$ [2] [5].

Adolescent patient with lumbar disc herniation has more severe symptoms as he always has a greater nerve root tension than in adult herniated lumber disc, which interferes with practicing his daily activities [3] [6].

The main aim of the treatment is to improve the symptoms and early return to normal life style and school. Conservative treatment is the first treatment for all patients with PLID (bed rest, muscle relaxants, anti-inflammatory, analgesics and physiotherapy) for at least6 weeks. In Kuirahara A. et al. study done in 1980, only $40 \%$ of patients responded to conservative treatment [7]. We noticed that many surgeons prefer not to do surgery for adolescents with PLID mostly due to fear of failed back surgery in this young age.

Surgical treatment has good results and excellent outcome and many studies recommend it after failure of conservative treatment [7] [8].

We reviewed our results in surgical treatment of PLID in adolescents over a period of 5 years (January 2014 to January 2019) to assess outcome of surgical treatment of PLID in this young age and answer a question if it really carries a high risk of failure or recurrence or not.

Low back pain and sciatica were the most common clinical presentation in our study (100\% of patients), the same as Durham SR, et al. [9] study and Abd El-kader et al., who reported $80 \%$ of patients included in his study complained of back pain [5].

In our study, the most common cause of lumber disc herniation in adolescent patients was lifting heavy objects. In Durham SR. et al. study, most patients have history of trauma before onset of the pain [9].

In our study MRI was the diagnostic method of choice for PLID. 14 (70\%) patients had disc location posterolateral, while $6(30 \%)$ patients had central disc. This is consistent with Abd El-Kader study [5].

The most common involved level was $\mathrm{L} 4 / 5$ ( $80 \%$ of patients), this was the same result of PragyanSarma, et al. study [4].

Three patients in our study (15\%) had complications post-operative as all the 3 patients had persistent low back pain which was less in severity than their pain before operation. Patients improved on physiotherapy and muscle relaxants. This result is close to Abd El-Kader [5] as he had 3 patients with persistent low back pain (12\%) with a total complication rate $24 \%$. Ahn Y et al. reported persistent back pain was the most common complication in adolescent [1].

Pragyan Sarma et al., he reported no recurrence in his study [4]. In our study there is only one case (5\%) with recurrence of L4/5 disc herniation and new L5/S1 disc herniation after 2 years of the first surgery and a second surgery was done for him. Chen LH et al. had also one patient with recurrence of PLID 3 months after first surgery and treated with second operation [8]. 
The overall results of surgery of PLID in adolescent were satisfactory in our study as all patients returned to their normal life style within 3 to 4 weeks after surgery with minimal restrictions like heavy weight lifting, this usually takes longer time in conservative treatment with more restrictions and difficulty in practicing the daily activities and more chance for the severe symptoms to reoccur. Also, Kuh et al., reported excellent results after surgery in adolescent patient [10]. Deluca PF. et al. reported more favorable results of surgical treatment than conservative one [11].

\section{Conclusion}

PLID in adolescent is very rare. Lifting heavy objects and trauma are the main causes in the adolescent patients. Surgical treatment when indicated, gives satisfactory outcome, low rate of complications, low rate of recurrence and early return to normal life activities.

\section{Recommendation}

We recommend making a further study with increase of the number of patients by sharing the experience of multiple centers and comparing the results of surgical treatment with the results of conservative treatment.

\section{Conflicts of Interest}

The authors declare no conflicts of interest regarding the publication of this paper.

\section{References}

[1] Ahn, Y. and Lee, S.-H. (2010) Outcome Predictors of Percutaneous Endoscopic Lumbar Discectomy and Thermal Annuloplasty for Discogenic Low Back Pain. Acta Neurochirurgica, 152, 1695-1702. https://doi.org/10.1007/s00701-010-0726-2

[2] Luukkonen, M., Partanen, K. and Vapalahti, M. (1997) Lumbar Disc Herniations in Children: A Long-Term Clinical and Magnetic Resonance Imaging Follow-up Study. British Journal of Neurosurgery, 11, 280-285. https://doi.org/10.1080/02688699746041

[3] Dang, L. and Liu, Z. (2010) A Review of Current Treatment for Lumbar Disc Herniation in Children and Adolescents. European Spine Journal, 19, 205-214. https://doi.org/10.1007/s00586-009-1202-7

[4] Sarma, P., Thirupathi, R.T., Srinivas, D. and Somanna, S. (2016) Adolescent Prolapsed Lumbar Intervertebral Disc: Management Strategies and Outcome. Journal of Pediatric Neurosciences, 11, 20-24. https://doi.org/10.4103/1817-1745.181259

[5] Abd El-Kader, H.E.-B. (2014) Lumbar Disc Herniation in Adolescents. Clinical Experience and Surgical Outcome. Egyptian Journal of Neurosurgery, 29, 45-50.

[6] Ozgen, S., Konya, D., Toktas, O.Z., Dagcinar, A. and Ozek, M.M. (2007) Lumbar Disc Herniation in Adolescence. Pediatric Neurosurgery, 43, 77-81. https://doi.org/10.1159/000098377

[7] Kurihara, A. and Kataoka, O. (1980) Lumbar Disc Herniation in Children and Adolescents. A Review of 70 Operated Cases and Their Minimum 5-Year Follow-up 
Studies. Spine, 5, 443-451. https://doi.org/10.1097/00007632-198009000-00009

[8] Chen, L.-H., Chang, C.-H., Lee, Z.-L., et al. (2004) Intervertebral Disc Herniation in Adolescents. Chang Gung Medical Journal, 27, 22-28.

[9] Durham, S.R., Sun, P.P. and Sutton, L.N. (2000) Surgically Treated Lumbar Disc Disease in the Pediatric Population: An Outcome Study. Journal of Neurosurgery, 92, 1-6. https://doi.org/10.3171/spi.2000.92.1.0001

[10] Kuh, S.-U., Kim, Y.-S., Cho, Y.-E., et al. (2005) Surgical Treatments for Lumbar Disc Disease in Adolescent Patients; Chemonucleolysis/Microsurgical Discectomy/PLIF with Cages. Yonsei Medical Journal, 46, 125-132. https://doi.org/10.3349/ymj.2005.46.1.125

[11] DeLuca, P.F., Mason, D.E., Weiand, R., Howard, R. and Bassett, G.S. (1994) Excision of Herniated Nucleus Pulposus in Children and Adolescents. Journal of Pediatric Orthopaedics, 14, 318-322. https://doi.org/10.1097/01241398-199405000-00008 